\title{
Atrial fibrillation: the role of common and rare genetic variants
}

\author{
Morten S Olesen ${ }^{\star, 1,2,4}$, Morten W Nielsen ${ }^{1,2,4}$, Stig Haunsø $ø^{1,2,3}$ and Jesper H Svendsen ${ }^{1,2,3}$
}

Atrial fibrillation (AF) is the most common cardiac arrhythmia affecting $1-2 \%$ of the general population. A number of studies have demonstrated that AF, and in particular lone AF, has a substantial genetic component. Monogenic mutations in lone and familial AF, although rare, have been recognized for many years. Presently, mutations in $\mathbf{2 5}$ genes have been associated with AF. However, the complexity of monogenic AF is illustrated by the recent finding that both gain- and loss-of-function mutations in the same gene can cause AF. Genome-wide association studies (GWAS) have indicated that common single-nucleotide polymorphisms (SNPs) have a role in the development of AF. Following the first GWAS discovering the association between PITX2 and AF, several new GWAS reports have identified SNPs associated with susceptibility of AF. To date, nine SNPs have been associated with AF. The exact biological pathways involving these SNPs and the development of AF are now starting to be elucidated. Since the first GWAS, the number of papers concerning the genetic basis of AF has increased drastically and the majority of these papers are for the first time included in a review. In this review, we discuss the genetic basis of AF and the role of both common and rare genetic variants in the susceptibility of developing AF. Furthermore, all rare variants reported to be associated with AF were systematically searched for in the Exome Sequencing Project Exome Variant Server. European Journal of Human Genetics (2014) 22, 297-306; doi:10.1038/ejhg.2013.139; published online 10 July 2013

Keywords: Ione AF; GWAS; PITX2

\section{INTRODUCTION}

Atrial fibrillation (AF) is a common supraventricular arrhythmia affecting $1-2 \%$ of the general population. The prevalence is increasing and is estimated to be doubled by $2040 .^{1,2}$ In most cases, AF is associated with cardiac risk factors such as hypertensive, ischemic and/or structural heart disease. ${ }^{3,4}$ However, a subgroup of patients presents with $\mathrm{AF}$ in the absence of predisposing factors, a condition called 'lone AF', accounting for $10-20 \%$ of the total number of patients with $\mathrm{AF}^{5}$

The mechanisms underlying AF are not fully understood but a heterogeneous model, based on the interaction of multiple substrates and triggers, is thought to underlie the pathophysiology of the disease. Lone AF has been suggested to be a primary electrical disease caused by disturbances in ionic currents and a genetic cause of these types of electrical disturbances is becoming increasingly recognized. ${ }^{6}$

A number of studies have demonstrated that AF and in particular lone AF have a substantial genetic component. ${ }^{7-13}$ Oyen et al ${ }^{14}$ have recently shown that an individual's risk of developing lone AF at a young age, increases drastically with both increasing number of relatives with lone AF and decreasing age at onset of the disease in these relatives, indicating an underlying genetic component in early onset lone AF.

Evidence for a heritable component of more common forms of AF has only recently been recognized. Fox et $a l^{11}$ studied the inherited predisposition for $\mathrm{AF}$ in $>5000$ individuals and showed that, the development of AF in the offspring was independently associated with parental AF. Offspring of parents with AF had approximately a doubled 4-year risk of developing AF, even after adjusting for known risk factors such as hypertension, diabetes and myocardial infarction.

In this review, we discuss the genetic basis of $\mathrm{AF}$ and the role of both common and rare genetic variants in the susceptibility of developing AF.

\section{MATERIALS AND METHODS}

The review is based on an information retrieval carried out in Pubmed using the MeSH database and Google Scholar. A systematic literature search was performed to identify all studies published before April 2013, which investigated the genetic basis of AF. Searching with the query (('Atrial fibrillation' (MeSH)) OR (atrial fibrillation)) AND (('Genetics' (MeSH)) OR $\left(\right.$ genetic $\left.\left.^{\star}\right)\right)$ AND (('Mutation' (MeSH)) OR (mutation $\left.{ }^{\star}\right)$ OR ('Polymorphism, single nucleotide' (MeSH)) OR (polymorphism, single nucleotide) OR (monogenic ${ }^{\star}$ ) OR (GWAS)) yielded 527 articles. Only articles concerning the genetic basis of AF were included in this review. Small studies concerning common variants in genes not associated with $\mathrm{AF}$ were excluded, unless these studies have been replicated in other independent populations or convincing electrophysiology was presented, because of a high risk of false-positive associations. The reference list and related articles of each relevant publication were also examined to identify additional studies appropriate for inclusion in this literature study. Furthermore, rare variants associated with AF were systematically search for existence in NHLBI GO Exome Sequencing Project (ESP). The reference sequences used are: NM_000218 (KCNQ1), NM_000219 (KCNE1), NM_172201 (KCNE2), NM_005472 (KCNE3), NM_080671 (KCNE4), NM_012282 (KCNE5), NM_004980 (KCND3), NM_000238

\footnotetext{
${ }^{1}$ The Danish National Research Foundation Centre for Cardiac Arrhythmia (DARC), Copenhagen, Denmark; ${ }^{2}$ Laboratory for Molecular Cardiology, The Heart Centre, Rigshospitalet, University of Copenhagen, Copenhagen, Denmark; ${ }^{3}$ Department of Surgery and Medicine, Faculty of Health Sciences, University of Copenhagen, Copenhagen, Denmark

4These authors contributed equally to this work.

*Correspondence: Dr MS Olesen, Department of Cardiology, Laboratory for Molecular Cardiology, Section 9312, Copenhagen University Hospital, Rigshospitalet, Juliane Mariesvej 20, DK-2100, Copenhagen Ø, Denmark. Tel: + 45 35456506; Fax: + 45 35456500; E-mail: morten.salling.olesen@gmail.com

Received 15 January 2013; revised 28 April 2013; accepted 27 May 2013; published online 10 July 2013
} 
(KCNH2), NM_000891 (KCNJ2), NM_004982 (KCNJ8), NM_002234 (KCNA5), NM_005691 (ABCC9), NM_198056 (SCN5A), NM_001037 (SCN1B), NM_199037 (SCN1Bb), NM_004588 (SCN2B), NM_018400 (SCN3B), NM_153485 (NUP155), NM_000165 (GJA1), NM_005266 (GJA5), NM_006172 (NPPA), NM_002052 (GATA4), NM_005257 (GATA6), NM_005572 (LMNA), NM_004387 (NKX2-5) and NM_022469 (GREM2).

\section{RESULTS}

The role of common genetic variants

In recent years, genome-wide association studies (GWAS) have indicated that common single-nucleotide polymorphisms (SNPs) have a role in the development of AF. The first GWAS on AF showed that a SNP (rs2200733) located in proximity of the gene PITX2 on chromosome $4 \mathrm{q} 25$ was highly associated with $\mathrm{AF}^{15}$ Since then, a number of GWAS have identified new SNPs associated with AF. ${ }^{16-18}$ The GWAS linking these SNPs to AF were all performed in general AF populations and the biological pathway between the SNPs and the emergence of AF still remains to be solved.

In the following, current knowledge about the individual SNPs and their possible involvement in the pathogenesis of AF will shortly be presented (see Table 1).

\section{The $4 \mathrm{q} 25$ locus}

The SNP rs2200733 resides closest to the gene PITX2 encoding the paired-like transcription factor PITX2. It was the first SNP to be identified and has been the top hit in all GWAS. Substantial research has therefore been focusing on this gene. In the human heart, PITX2c is the major isoform expressed ${ }^{19}$ and is involved in the control of asymmetric cardiac morphogenesis. ${ }^{15,20}$ Chung et al ${ }^{21}$ have shown the association of a genetic variant on chromosome 4q25 with levels of PITX2c transcripts in left atrial tissue samples and knockout mouse models have indicated a critical role of the PITX2c in the development of the left atrium. ${ }^{22}$ Of note, PITX2c was in a recent study demonstrated to be a requisite for the development of a sleeve of cardiomyocytes extending from the left atrium to the initial portion of the pulmonary veins, which is believed to be the anatomical substrate for $\mathrm{AF}$ and the fundament for pulmonary vein isolation when an ablation strategy is chosen in an AF patient. ${ }^{23}$ In line with this, clinical and animal studies have demonstrated that ectopic foci of electrical activity arising from within the pulmonary veins and posterior left atrium have a substantial role in initiating and maintaining fibrillatory activity. ${ }^{24,25}$ In contrast to studies indicating a

Table 1 Summary of SNPs associated with AF

\begin{tabular}{|c|c|c|c|c|c|}
\hline SNP & $\begin{array}{l}\text { Chromosome } \\
\text { locus }\end{array}$ & Hg location & $\begin{array}{l}\text { Closest } \\
\text { gene }\end{array}$ & $\begin{array}{l}\text { Location } \\
\text { of SNP }\end{array}$ & Reference \\
\hline rs2200733 & $4 q 25$ & 4:111710 169 & PITX2 & $\begin{array}{l}\text { 150-kb } \\
\text { upstream }\end{array}$ & 15 \\
\hline rs2106261 & $16 q 22$ & $16: 73051620$ & ZFHX3 & Intronic & 16 \\
\hline rs13376333 & $1 q 21$ & $1: 154814353$ & KCNN3 & Intronic & 17 \\
\hline rs3807989 & $7 q 31$ & $7: 116186241$ & $\begin{array}{l}\text { CAV1/ } \\
\text { CAV2 }\end{array}$ & Intronic & 18 \\
\hline rs3903239 & 1q24 & $1: 170569317$ & PRRX1 & $\begin{array}{l}\text { 46-kb } \\
\text { upstream }\end{array}$ & 18 \\
\hline rs1152591 & $14 q 23$ & $14: 64680848$ & SYNE2 & Intronic & 18 \\
\hline rs10821415 & $9 q 22$ & 9:97 713459 & c9orf3 & Intronic & 18 \\
\hline rs7164883 & $15 q 24$ & $15: 73652174$ & HCN4 & Intronic & 18 \\
\hline rs10824026 & $10 q 22$ & 10:75421 208 & SYNPO2L & $\begin{array}{l}\text { 5-kb } \\
\text { upstream }\end{array}$ & 18 \\
\hline
\end{tabular}

All from GWAS. structural role of $P I T X 2 c$, a recently published study of heterozygous knockout $\left(P I T X 2 c^{+/-}\right)$mice showed that these mice have a normal cardiac morphology and function, whereas expression of calcium ion binding proteins, gap- and tight junctions and ion channels was changed. They furthermore showed that isolated PITX2 $c^{+/-}$mice hearts were susceptible to AF during programmed pacing, because of shortening of atrial action potential durations (APDs) and the effective refractory period (ERP). ${ }^{26}$ In line with these results, human studies have recently revealed that PITX2c expression is significantly decreased in patients with sustained AF, thus providing a molecular link between PITX2 loss-of-function and AF. ${ }^{27}$ Although a lot of studies indicate PITX2 as having a role in AF, evidence regarding the expression of PITX2 and its target genes in patients with $\mathrm{AF}$ is still missing. For instance, no studies regarding mRNA levels in atrial tissue of PITX2 and target proteins measured by $\mathrm{qPCR}$ are available. For further insight and overview figures for the role of PITX2 in AF pathogenesis, please see Liu et a ${ }^{28}$ and Xiao et al. ${ }^{29}$

\section{Other GWAS loci}

The SNP rs2106261 is located on chromosome 16q22 in an intronic region of transcription factor ZFHX3. The function of ZFHX3 in cardiac tissue is unknown but it is expressed in mouse hearts. ${ }^{30}$ The SNP rs13376333 is located on chromosome 1q21 in KCNN3, which encodes a calcium-activated potassium channel involved in atrial repolarization. In a rabbit burst-pacing model mimicking ectopic pulmonary vein foci, the pulmonary vein and atrial APD was shortened. This APD shortening was inhibited by apamin, a blocker of the calcium-activated potassium channels. ${ }^{31}$ This provides a possible basis of KCNN3 having a role in AF. The SNP rs3807989 is located close to the gene CAV1-encoding caveolin. CAV1 is expressed in atrial myocytes and is necessary for the development of caveolae involved in electric signal transduction. ${ }^{32}$ CAV1 knockout mice develop dilated cardiomyopathy and pulmonary hypertension. ${ }^{33}$ The SNP rs3903239 is located on chromosome 1q24, 46-kb upstream from the closest gene PRRX1 encoding a homeodomain transcription factor highly expressed in the developing heart. ${ }^{18}$ Knock-out mouse models have revealed that PRRX1 is necessary for the normal development of great vessels and lung vascularization. ${ }^{34,35}$ The SNP rs1152591 is located on chromosome 14q23, in an intron of the gene SYNE2 encoding nesprin 2, which is a linker of nucleoskeleton and cytoskeleton (LINC) protein involved in maintaining cellular architecture and nuclear integrity. ${ }^{36}$ It is highly expressed in heart and skeletal muscle, and mutations in SYNE2 have been identified in families with Emery-Dreifuss muscular dystrophy. A disease that also displays cardiac manifestations characterized by cardiomyopathy and cardiac conduction defects. ${ }^{18,37}$ The SNP rs 10821415 is located in an open reading frame on chromosome 9. Genes near this locus is FBP1 and FBP2, which is involved in gluconeogenesis. ${ }^{18}$ How this SNP could be involved in developing AF remains unknown. The SNP rs7164883 is located on chromosome $15 \mathrm{q} 24$ in an intron of the gene HCN4, which encodes the cardiac pacemaker channel responsible for the funny current $\left(\mathrm{I}_{\mathrm{f}}\right)$. The HCN4 channel is expressed in most of the conduction system and is the predominant isoform of the primary pacemaker in mouse hearts. ${ }^{38}$ Mutations in HCN4 have been associated with sinus node dysfunction. ${ }^{39,40}$ The SNP rs10824026 is located on chromosome 10q22, 5-kb upstream of SYNPO2L. ${ }^{18}$ Beqqali et al ${ }^{41}$ identified the gene as encoding a cytoskeletal protein, which is highly expressed in the Z-disc of cardiac and skeletal muscle. They renamed it CHAP, cytoskeletal heart-enriched actin-associated protein. CHAP was found to have an important role in skeletal and cardiac muscle development. 
Of note, Brugada et $a l^{42}$ identified the SYNPO2L locus as a susceptibility locus for AF in a family with autosomal dominant AF.

None of the GWAS hits are found in amino-acid-coding regions of the genes. One possible explanation for the association with $\mathrm{AF}$ is that these variants may function as regulators of an adjacent gene, perhaps by altering the function of a promoter or enhancer and thereby causing an up or downregulation of genes nearby. Intense research is ongoing in order to correlate the GWAS hits with mRNA expression of genes located in proximity of the regions where the SNPs resides. These research projects are complicated by the fact that the top hits from GWAS are not necessarily the disease causative variants and other variants in high linkage must also be taken into account. Furthermore, it is possible that a GWAS hit is in high linkage disequilibrium (LD) with a low frequent variant, as was shown to be the case for a variant associated with sick sinus syndrome. ${ }^{43}$ Thus, so far the mechanisms behind the association of the GWAS hits and AF still remain unresolved.

\section{THE ROLE OF RARE GENETIC VARIANTS}

Several genetic reports have revealed rare variants associated with AF in genes encoding cardiac gap junctions, signaling molecules, ion channels and accessory subunits. ${ }^{6}$ Most of these studies show either gain- or loss-of-function mutations in the genes encoding proteins contributing to cardiac depolarization or repolarization leading to increased susceptibility of AF.

These results support the two current conceptual models for AF. The first one being that cardiac action potential (cAP) shortening functions as a substrate for re-entry wavelets in the atria. ${ }^{44,45}$ The second one being that a prolonged ERP enhances the propensity for early afterdepolarization (EAD) and thereby, increasing the susceptibility to $\mathrm{AF}^{46}$ For a general introduction to cAP and involved ion channels, please see Nattel $^{44}$ and/or ShiroshitaTakeshita et al. ${ }^{47}$

In the following, current knowledge about rare variants in the individual genes and their possible involvement in the pathogenesis of $\mathrm{AF}$ will be presented.

\section{POTASSIUM CHANNEL MUTATIONS}

Chen et al ${ }^{48}$ revealed the first association between mutations in KCNQ1 and familial AF (see Table 2). The KCNQ1 gene encodes the pore-forming $\alpha$-subunit of the cardiac potassium channel $\mathrm{I}_{\mathrm{Ks}}$ involved in cardiac repolarization. They studied a four-generation Chinese family with $\mathrm{AF}$ and indentified a mutation in all of the affected family members. Functional studies showed an increase in current density and altered gating and kinetic properties. This suggests a gain-offunction effect resulting in shortening of APD and reduction of the ERP. ${ }^{6}$ A number of gain-of-function mutations in KCNQ1 have been identified since (see Table 2). ${ }^{49-53}$ Just recently, Bartos et al $l^{54}$ identified a gain-of-function mutation in KCNQ1 with high penetrance in five different families with early-onset AF. In addition to AF, several of the family members had abnormal QTc intervals, syncope or experienced sudden cardiac arrest or death.

The regulatory $\beta$-subunits of the $\mathrm{I}_{\mathrm{Ks}}$ channel are encoded by five genes, KCNE1-5. In a recent study by Olesen et al ${ }^{55}$ two nonsynonymous mutations in KCNE1 was associated with AF. In heterologous expression systems, both mutations showed significant gain-of-function for $\mathrm{I}_{\mathrm{Ks}}$. Yang et $a l^{56}$ evaluated 28 unrelated Chinese kindred's with $\mathrm{AF}$ and identified a mutation in two probands in the KCNE2 gene. The mutation showed a gain-of-function effect on $\mathrm{I}_{\mathrm{Ks}}$. Lundby et al ${ }^{12}$ identified a mutation in KCNE3 in a patient with lone $\mathrm{AF}$ and electrophysiological recordings displayed a gain-of-function effect on $\mathrm{I}_{\mathrm{Ks}}$. Recently, a mutation in KCNE4 was identified by Mann $e t a l^{57}$ in a patient with AF. The functional consequence of this mutation is uncertain but the authors describe a possible change in $\mathrm{I}_{\mathrm{Ks}}, \mathrm{I}_{\mathrm{Kr}}$ and $\mathrm{I}_{\mathrm{to}}$. Finally, Ravn et al. ${ }^{13}$ found a missense mutation in KCNE5 in 1 of 158 AF patients resulting in a gain-of-function effect on $\mathrm{I}_{\mathrm{Ks}}$.

The KCNH2 gene encodes the $\alpha$-subunit of $\mathrm{I}_{\mathrm{Kr}}$. A mutation in this gene was identified by Hong et $a^{58}$ in a family with both short QT and AF, which suggest an overlap in phenotypes. Previously, the mutation has been shown to drastically increase $I_{\mathrm{Kr}}$ and thus displaying gain-of-function. ${ }^{59}$ Mann $e t a l^{57}$ have revealed additional mutations in $\mathrm{KCNH} 2$ in AF patients (see Table 2).

The KCNJ2 gene encodes the inward rectifier channel Kir2.1 that mediates the current $\mathrm{I}_{\mathrm{K} 1}$ involved in both the late phase of repolarization (phase 3) and the phase of maintaining resting membrane potential (phase 4). Xia et al ${ }^{60}$ identified a missense mutation in KCNJ2 in a Chinese kindred. Functional analysis of the mutant demonstrated a gain-of-function consequence on the Kir2.1 current.

Recently, Delaney et al ${ }^{61}$ found a missense mutation in KCNJ8 in a cohort of lone AF patients. The KCNJ8 gene encodes the cardiac $\mathrm{K}_{\mathrm{ATP}}$ channel Kir6.1. The Kir6.1 channel facilitates a non-voltage-gated inwardly rectifying potassium current, leading to a shortening of the APD under conditions of metabolic stress. ${ }^{61}$ In a previous study, the mutation was shown to display a gain-of-function effect. ${ }^{62}$

The KCNA5 gene encodes the atria-specific $\mathrm{K}_{\mathrm{v}} 1.5$ channel responsible for the ultra-rapid delayed rectifier potassium current, $I_{\text {Kur }}$ involved in cardiac repolarization. Olson et al ${ }^{63}$ identified a nonsense mutation in a familial case of AF. The mutation displayed a lossof-function effect resulting in action potential prolongation and EAD. A number of mutations have since then been identified (see Table 2). ${ }^{46,64-66}$

The ABCC9 gene encodes the SUR2A $\mathrm{K}_{\mathrm{ATP}}$ channel subunit involved in maintaining electrical stability under stress, including adrenergic challenge. Olson et al ${ }^{67}$ identified a missense mutation in the $A B C C 9$ gene in a female case with early-onset AF originating from the vein of Marshall. The mutation displayed loss-of-function.

\section{SODIUM CHANNEL MUTATIONS}

The SCNA5 gene encodes the $\alpha$-subunit of the cardiac sodium channel responsible for the $\mathrm{I}_{\mathrm{Na}}$ current involved in cardiac depolarization (see Table 3). Darbar et al ${ }^{68}$ identified rare variants in SCN5A in familial form of AF. Interestingly, several of the variants caused overlapping phenotypes with cardiomyopathy. Recently, Olesen et a 69 identified eight mutations in SCN5A in a cohort of lone AF patients. Functional investigations of the mutations revealed both compromised transient peak current and increased sustained current. These results indicate that both gain- or loss-of-function alterations in cardiac sodium current are involved in early-onset AF.

$S C N 1 B-4 B$ encodes the modifying $\beta$-subunits $(\operatorname{Nav} \beta 1-\beta 4)$ of the cardiac sodium channel. Watanabe et $a l^{70}$ found two nonsynonymous loss-of-function mutations in $S C N 1 B$ and two in $S C N 2 B$ in a cohort of $480 \mathrm{AF}$ patients. Wang et $a l^{71}$ found a lossof-function mutation in $S C N 3 B$ in another lone AF cohort. Moreover, Olesen et $a l^{72}$ identified three non-synonymous mutations in $S C N 3 B$, which displayed a loss-of-function effect in the sodium current. One of the variants p.(Leu10Pro) has also been identified in a patient with Brugada syndrome $(\mathrm{BrS}){ }^{73}$

$S C N 1 B b$ encodes a second $\beta 1$ transcript, named Nav $\beta 1 B$. Olesen et $a l^{74}$ identified a missense mutation in $S C N 1 B b$ in two patients with lone $\mathrm{AF}$ as well as one patient with BrS. The same mutation was 
Table 2 Summary of potassium channel rare variants associated with AF

\begin{tabular}{|c|c|c|c|c|c|c|c|c|c|}
\hline Gene & Gene product & $\begin{array}{l}\text { Nucleotide } \\
\text { substitution }\end{array}$ & $\begin{array}{l}\text { Amino-acid } \\
\text { substitution }\end{array}$ & $\begin{array}{c}\text { Documented } \\
\text { family } \\
\text { co-segregation }\end{array}$ & $\begin{array}{l}\text { Electrophysiological } \\
\text { consequence }\end{array}$ & Reference & $\begin{array}{c}\text { Found in } \\
\text { ESP EA minor/minor/ } \\
\text { minor/major }\end{array}$ & $\begin{array}{c}\text { Found in } \\
\text { ESP AA minor/minor/ } \\
\text { minor/major }\end{array}$ & $\begin{array}{c}\text { Found in } \\
\text { ESP all minor/minor/ } \\
\text { minor/major }\end{array}$ \\
\hline \multirow[t]{7}{*}{$K C N Q 1$} & \multirow[t]{7}{*}{$\alpha$-Subunit of $I_{K s}$} & c. $40 \mathrm{C}>\mathrm{T}$ & p.(Arg14Cys) & Yes & Gain-of-function & 53 & $0 / 0$ & $0 / 0$ & $0 / 0$ \\
\hline & & $\begin{array}{l}\text { c.160_168ins } \\
\text { ATCGCGCCC }\end{array}$ & p.(54_56inslleAlaPro) & Yes & Gain-of-function & 52 & $0 / 0$ & $0 / 0$ & $0 / 0$ \\
\hline & & c. $418 \mathrm{~A}>\mathrm{G}$ & p.(Ser140 Gly) & Yes & Gain-of-function & 48 & $0 / 0$ & $0 / 0$ & $0 / 0$ \\
\hline & & c. $421 \mathrm{G}>\mathrm{A}$ & p.(Val141Met) & No & Gain-of-function & 49 & $0 / 0$ & $0 / 0$ & $0 / 0$ \\
\hline & & c. $625 \mathrm{C}>\mathrm{T}$ & p.(Ser209Pro) & Yes & Gain-of-function & 50 & $0 / 0$ & $0 / 0$ & $0 / 0$ \\
\hline & & c. $692 \mathrm{G}>\mathrm{A}$ & p.(Arg231 His) & Yes & Gain-of-function & 54 & $0 / 0$ & $0 / 0$ & $0 / 0$ \\
\hline & & c. $693 \mathrm{C}>\mathrm{T}$ & p.(Arg231Cys) & Yes & Gain-of-function & 51 & $0 / 0$ & $0 / 0$ & $0 / 0$ \\
\hline \multirow[t]{2}{*}{ KCNE1 } & \multirow[t]{2}{*}{$\beta$-Subunit of $\mathrm{I}_{\mathrm{Ks}}$} & c. $74 \mathrm{C}>\mathrm{T}$ & p.(Gly25Val) & No & Gain-of-function & 55 & $0 / 0$ & $0 / 0$ & $0 / 0$ \\
\hline & & c. $179 \mathrm{G}>\mathrm{A}$ & p.(Gly60Asp) & Yes & Gain-of-function & 55 & $0 / 0$ & $0 / 0$ & $0 / 0$ \\
\hline KCNE2 & $\beta$-Subunit of $\mathrm{I}_{\mathrm{KS}}$ & c. $79 \mathrm{C}>\mathrm{T}$ & p.(Arg27Cys) & Yes & Gain-of-function & 56 & $0 / 0$ & $0 / 0$ & $0 / 0$ \\
\hline KCNE3 & $\beta$-Subunit of $I_{K s}$ & c. $49 \mathrm{G}>\mathrm{A}$ & p.(Val17Met) & No & Gain-of-function & 12 & $0 / 0$ & $0 / 0$ & $0 / 0$ \\
\hline KCNE4 & $\beta$-Subunit of $I_{K s}$ & c. $422 A>C$ & p.(Glu141Ala) & $?$ & Possible change & 57 & $0 / 5$ & $0 / 0$ & $0 / 5$ \\
\hline KCNE5 & $\beta$-Subunit of $I_{K s}$ & c. $193 \mathrm{C}>\mathrm{T}$ & p.(Leu65Phe) & No & Gain-of-function & 13 & $0 / 0$ & $0 / 0$ & $0 / 0$ \\
\hline \multirow[t]{3}{*}{ KCND3 } & Kv4.3 & c. $5 \mathrm{C}>\mathrm{A}$ & p.(Ala2Glu) & $?$ & No change & 57 & $0 / 0$ & $0 / 0$ & $0 / 0$ \\
\hline & & c. $641 A>G$ & p.(Lys214Arg) & $?$ & No change & 57 & $0 / 4$ & $0 / 0$ & $0 / 4$ \\
\hline & & c. $1633 G>C$ & p.(Ala545Pro) & $?$ & Gain-of-function & 118 & $0 / 0$ & $0 / 0$ & $0 / 0$ \\
\hline \multirow[t]{3}{*}{$\mathrm{KCNH} 2$} & $\alpha$-Subunit of $I_{\mathrm{Kr}}$ & c. $526 C>T$ & p.(Arg176Trp) & No & Loss-of-function & 57,121 & $0 / 0$ & $0 / 0$ & $0 / 0$ \\
\hline & & c. $1330 \mathrm{G}>\mathrm{A}$ & p.(Glu444Lys) & Yes & Loss-of-function & 57 & $0 / 0$ & $0 / 0$ & $0 / 0$ \\
\hline & & c. $1764 C>G$ & p.(Asn588Lys) & Yes & Gain-of-function & 58,59 & $0 / 0$ & $0 / 0$ & $0 / 0$ \\
\hline KCNJ2 & Kir2.1 & c. $277 G>A$ & p.(Val93lle) & Yes & Gain-of-function & 60 & $0 / 2$ & $0 / 1$ & $0 / 3$ \\
\hline KCNJ8 & Kir6.1 & c. $1265 \mathrm{C}>\mathrm{T}$ & p.(Ser422Leu) & $?$ & Gain-of-function & 61,62 & $0 / 19$ & $0 / 1$ & $0 / 20$ \\
\hline \multirow[t]{12}{*}{ KCNA5 } & Kv1.5 & c. $143 \mathrm{~A}>\mathrm{G}$ & p.(Glu48Gly) & No & Gain-of-function & 66 & $0 / 0$ & $0 / 0$ & $0 / 0$ \\
\hline & & c. $211 \_243$ & p.(71_81del) & Yes & Loss-of-function & 65 & NA & NA & NA \\
\hline & & c. $464 \mathrm{~A}>\mathrm{G}$ & p.(Tyr155Cys) & No & Loss-of-function & 66 & $0 / 0$ & $0 / 0$ & $0 / 0$ \\
\hline & & c. $913 \mathrm{G}>\mathrm{A}$ & p.(Ala305Thr) & Yes & Gain-of-function & 66 & $0 / 0$ & $0 / 0$ & $0 / 0$ \\
\hline & & c. $964 G>C$ & p.(Asp322His) & No & Gain-of-function & 66 & $0 / 0$ & $0 / 0$ & $0 / 0$ \\
\hline & & c. $1123 \mathrm{G}>\mathrm{T}$ & p.(Glu375Ter) & Yes & Loss-of-function & 63 & $0 / 0$ & $0 / 0$ & $0 / 0$ \\
\hline & & c. $1407 C>A$ & p.(Asp469Glu) & No & Loss-of-function & 66 & $0 / 0$ & $0 / 0$ & $0 / 0$ \\
\hline & & c. $1462 C>T$ & p.(Pro488Ser) & No & Loss-of-function & 66 & $0 / 0$ & $0 / 0$ & $0 / 0$ \\
\hline & & c. $1580 \mathrm{C}>\mathrm{T}$ & p.(Thr527Met) & Yes & Loss-of-function & 46,64 & $0 / 0$ & $0 / 0$ & $0 / 0$ \\
\hline & & c. $1703 \mathrm{G}>\mathrm{T}$ & p.(Gly568Val) & Yes & Gain-of-function & 57 & $0 / 3$ & $0 / 0$ & $0 / 3$ \\
\hline & & c. $1727 \mathrm{C}>\mathrm{T}$ & p.(Ala576Val) & Yes & Loss-of-function & 46 & $0 / 0$ & $0 / 0$ & $0 / 0$ \\
\hline & & c. $1828 \mathrm{G}>\mathrm{A}$ & p.(Glu610Lys) & Yes & Loss-of-function & 46 & $0 / 0$ & $0 / 0$ & $0 / 0$ \\
\hline$A B C C 9$ & $\mathrm{~K}_{\text {ATP }}$ channel & c. $4640 \mathrm{C}>\mathrm{T}$ & p.(Thr1547lle) & $?$ & Loss-of-function & 67 & $0 / 0$ & $0 / 0$ & $0 / 0$ \\
\hline
\end{tabular}

Abbreviations: AA, African American; EA, European American; ESP, NHLBI GO Exome Sequencing Project; NA, data regarding major InDel is not available in EVS.

identified by $\mathrm{Hu}$ et $a l^{75}$ in another $\mathrm{BrS}$ patient and functional data revealed that the mutation resulted in a $57 \%$ decrease in the peak sodium current while the Kv4.3 current was increased by $71 \%$ suggesting a combined effect with loss-of-function of the sodium channel current and a gain-of-function of the transient outward potassium current. On this basis, mutations in $S C N 1 B b$ could be susceptible variants for both $\mathrm{AF}$ and/or BrS.

\section{NON-ION CHANNEL MUTATIONS}

The NUP155 gene encodes a nucleoporin, an essential component of the nuclear pore complex, a complex involved in nucleo-cytoplasmic transport (see Table 4). The gene is located on chromosome $5 \mathrm{q}_{13} .^{76}$ Oberti et al ${ }^{77}$ mapped an AF locus to chromosome $5 \mathrm{q} 13$ in a large AF family with an autosomal recessive inheritance pattern. Subsequently, Zhang et $a l^{78}$ revealed that the above mentioned locus was NUP155 and identified a homozygous mutation in NUP155 in all the affected family members. Heterozygous (NUP155 $5^{+/-}$) knockout mice showed AF phenotype.

NPPA encodes atrial natriuretic peptide, a circulating hormone produced in cardiac atria involved in the regulation of blood pressure through natriuresis, diuresis and vasodilatation. ${ }^{79}$ Hodgson-Zingman et $a l^{80}$ described a family with $\mathrm{AF}$ and an autosomal dominant pattern of inheritance. In this family, a heterozygous frameshift mutation in NPPA was detected and the mutation co-segregated with AF. The mutant peptide was shown to shorten atrial APD and the ERP in a rat heart model. Recently, Abraham et $a l^{52}$ found a novel missense mutation in NPPA that was shown to co-segregate with early-onset AF. In the same cohort, the investigators found a KCNQ1 mutation and functional analysis of the two mutations yielded strikingly similar $\mathrm{I}_{\mathrm{Ks}}$ gain-of-function effects.

The GATA4 and GATA6 genes encode cardiac transcription factors. They work synergistically with NKX2-5 in regulation of target gene expression, especially those involved in cardiogenesis. ${ }^{81}$ Posch et al ${ }^{82}$ found a GATA4 mutation in one patient with familial lone AF in a lone AF cohort. A second mutation was found in a patient with sporadic lone AF. Additional studies have identified mutations in GATA4 in different families, which co-segregated with AF and displayed decreased transcriptional effect. ${ }^{83-85}$ Yang et al ${ }^{86}$ reported two heterozygous GATA6 mutations in two of 110 probands with familial AF. Each mutation co-segregated with AF transmitted as an autosomal dominant trait. The mutation was also associated with congenital cardiac defects in three AF patients in the families of the two probands. Additional studies have identified novel mutations in GATA6 that co-segregated with AF and resulted in decreased transcriptional activity. ${ }^{87,88}$

The LMNA gene encodes lamin $\mathrm{A} / \mathrm{C}$, an intermediate filament protein associated with the inner nuclear membrane. Mutations in this gene have been associated with many diseases such as dilated cardiomyopathy and muscular dystrophy. ${ }^{89}$ Beckmann et a $l^{90}$ identified a heterozygous missense mutation in LMNA in a family with AF as well as SVT, VF, muscle weakness and sudden cardiac death. Just recently, Saj et a ${ }^{91}$ found two variants in two unrelated probands with AF, one of them with episodes of AV-block, the other with reduced left ventricular contractile function (ejection fraction of $30 \%$ ), left bundle branch block and family history of heart disease.

The GREM2 gene encodes the bone morphogenetic protein (BMP) antagonist gremlin-2. Just recently, Müller et a ${ }^{92}$ identified a variant 
Table 3 Summary of sodium channel rare variants associated with AF

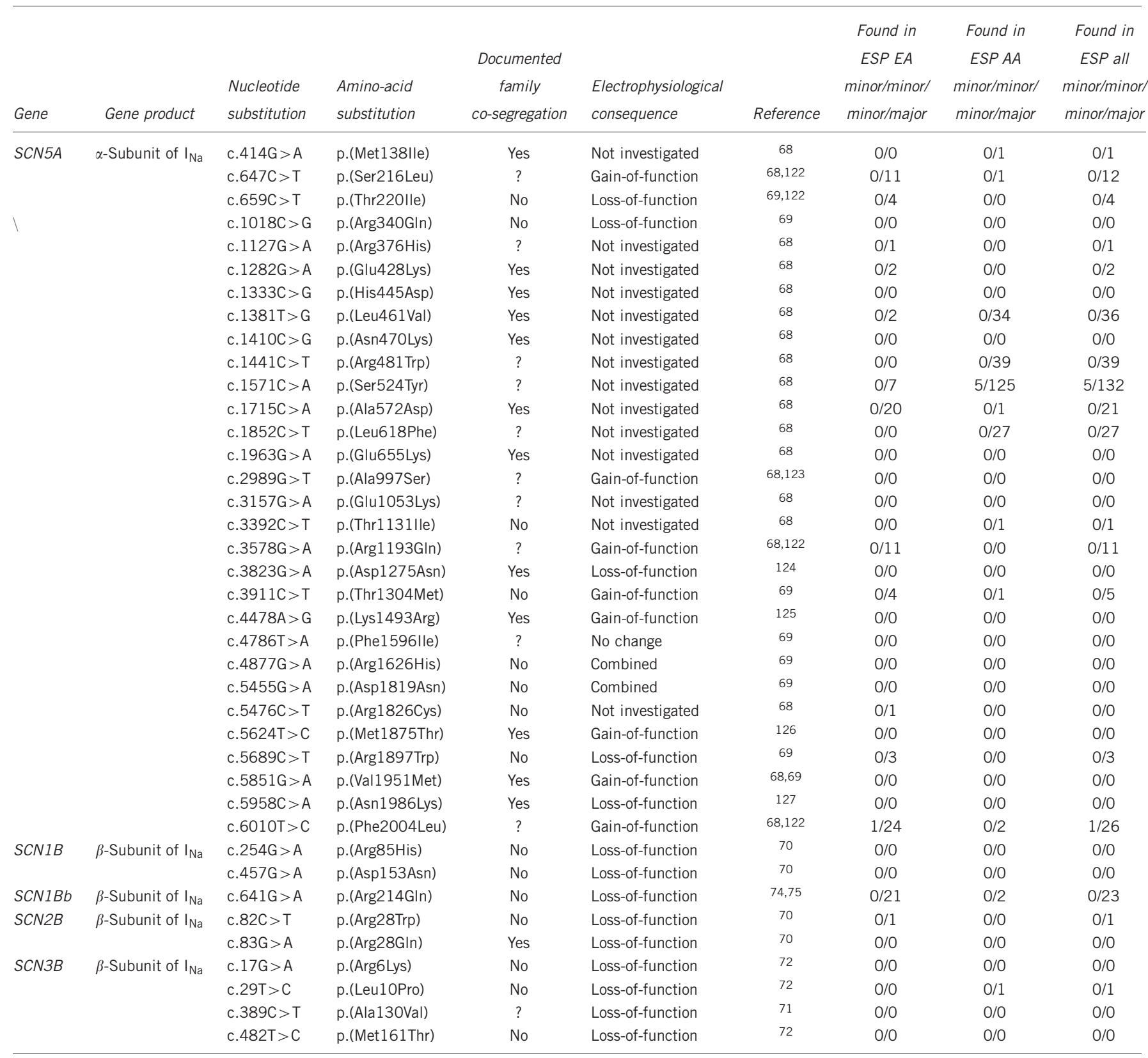

Abbreviations: AA, African American; EA, European American; ESP, NHLBI GO Exome Sequencing Project.

in GREM2 in two probands of a lone AF cohort. The variant was twofold more potent in antagonizing BMP than wild type. In a zebra fish model GREM2 was shown to be required for cardiac laterality and atrial differentiation. GREM2 over activity resulted in slower cardiac contraction rates and slower contraction velocity. Interestingly, PITX2 (the top hit in GWAS) is regulated by BMP, suggesting that GREM2 is acting upstream PITX2.

\section{SOMATIC MUTATIONS}

The GJA1 and GJA5 genes encode connexin43 and connexin40, respectively, which are gap-junction proteins in the atrial myocardium responsible for cell-to-cell conduction of the action potential (see Table 4). Thibodeau et a $l^{93}$ identified a frameshift mutation, caused by a single-nucleotide deletion in GJA1, in atrial tissue in 1 of 10 unrelated lone AF patients. The mutation was absent from lymphocyte DNA of the patient indicating genetic mosaicism. The mutant protein demonstrated a trafficking defect leading to an intracellular retention of the protein and a failure of electric coupling between cells. Gollob et al $l^{94}$ identified four heterozygous missense mutations in GJA5 in 4 of 15 idiopathic AF patients. Of note, in three of the patients the mutations were found to be somatic, suggesting that such mutations also could be involved in AF susceptibility. The mutant proteins revealed impaired intracellular transport or reduced intercellular electrical coupling. This may lead to conduction heterogeneity and re-entrant circuits. Recently, Christophersen et al ${ }^{95}$ replicated the germline mutation in GJA5 
Table 4 Summary of non-ion channel rare variants associated with AF

\begin{tabular}{|c|c|c|c|c|c|c|c|c|c|}
\hline Gene & Gene product & $\begin{array}{l}\text { Nucleotide } \\
\text { substitution }\end{array}$ & $\begin{array}{l}\text { Amino-acid } \\
\text { substitution }\end{array}$ & $\begin{array}{c}\text { Documented } \\
\text { family } \\
\text { co-segregation }\end{array}$ & $\begin{array}{l}\text { Electrophysiological } \\
\text { consequence }\end{array}$ & Reference & $\begin{array}{c}\text { Found in } \\
\text { ESP EA } \\
\text { minor/minor/ } \\
\text { minor/major }\end{array}$ & $\begin{array}{l}\text { Found in } \\
\text { ESP AA } \\
\text { minor/minor/ } \\
\text { minor/major }\end{array}$ & $\begin{array}{c}\text { Found in } \\
\text { ESP all } \\
\text { minor/minor/ } \\
\text { minor/major }\end{array}$ \\
\hline NUP155 & Nucleoporin & c. $1172 \mathrm{G}>\mathrm{A}$ & p.(Arg391His) & Yes & Loss-of-function & 77,78 & $0 / 0$ & $0 / 0$ & $0 / 0$ \\
\hline GJA1 & Connexin43 & c.932delC & Frameshift ${ }^{a}$ & No & Loss-of-function & 93 & $0 / 0$ & $0 / 0$ & $0 / 0$ \\
\hline \multirow[t]{9}{*}{ GJA5 } & Connexin 40 & c. $113 G>A$ & p.(Gly38Asp) & No & Loss-of-function & 94 & $0 / 0$ & $0 / 0$ & $0 / 0$ \\
\hline & & c. $145 \mathrm{C}>\mathrm{T}$ & p.(GIn49Ter) & Yes & Loss-of-function & 97 & $0 / 0$ & $0 / 0$ & $0 / 0$ \\
\hline & & c. $223 \mathrm{~A}>\mathrm{T}$ & p.(Ile75Phe) & Yes & Loss-of-function & 98 & $0 / 0$ & $0 / 0$ & $0 / 0$ \\
\hline & & c. $253 G>A$ & p.(Val85lle) & Yes & Not investigated & 96 & $0 / 0$ & $0 / 0$ & $0 / 0$ \\
\hline & & c. $262 \mathrm{C}>\mathrm{T}$ & p.(Pro88Ser) & No & Loss-of-function & 94 & $0 / 0$ & $0 / 0$ & $0 / 0$ \\
\hline & & c. $286 \mathrm{G}>\mathrm{T}$ & p.(Ala96Ser) & No & Loss-of-function & 94 & $0 / 0$ & $0 / 0$ & $0 / 0$ \\
\hline & & c. $487 \mathrm{~A}>\mathrm{G}$ & p.(Met163Val) $)^{a}$ & No & Loss-of-function & 94 & $0 / 0$ & $0 / 0$ & $0 / 0$ \\
\hline & & c. $661 C>A$ & p.(Leu221Ile) & Yes & Not investigated & 96 & $0 / 0$ & $0 / 0$ & $0 / 0$ \\
\hline & & c. $685 \mathrm{C}>\mathrm{A}$ & p.(Leu229Met) & Yes & Not investigated & 96 & $0 / 0$ & $0 / 0$ & $0 / 0$ \\
\hline \multirow[t]{3}{*}{ NPPA } & ANP & c. $190 \mathrm{~A}>\mathrm{C}$ & p.(Ser64Arg) & Yes & Gain-of-function & 52 & $0 / 24$ & $0 / 2$ & $0 / 26$ \\
\hline & & c. $350 \mathrm{C}>\mathrm{T}$ & p.(Ala117Val) & Yes & Not investigated & 117 & $0 / 0$ & $0 / 0$ & $0 / 0$ \\
\hline & & c.456_457delAA & Frameshift & Yes & Gain-of-function & 80 & $0 / 0$ & $0 / 0$ & $0 / 0$ \\
\hline \multirow[t]{8}{*}{ GATA4 } & Transcription & c. $46 \mathrm{G}>\mathrm{T}$ & p.(Gly16Cys) & Yes & Loss-of-function & 84 & $0 / 0$ & $0 / 0$ & $0 / 0$ \\
\hline & & c. $82 \mathrm{C}>\mathrm{G}$ & p.(His28Asp) & Yes & Loss-of-function & 84 & $0 / 0$ & $0 / 0$ & $0 / 0$ \\
\hline & & c. $112 \mathrm{~T}>\mathrm{G}$ & p.(Tyr38Asp) & Yes & Loss-of-function & 85 & $0 / 0$ & $0 / 0$ & $0 / 0$ \\
\hline & & c. $209 G>C$ & p.(Ser70Thr) & Yes & Loss-of-function & 83 & $0 / 0$ & $0 / 0$ & $0 / 0$ \\
\hline & & c. $307 \mathrm{C}>\mathrm{G}$ & p.(Pro103Ala) & Yes & Loss-of-function & 85 & $0 / 0$ & $0 / 0$ & $0 / 0$ \\
\hline & & c. $479 G>C$ & p.(Ser160Thr) & Yes & Loss-of-function & 83 & $0 / 0$ & $0 / 0$ & $0 / 0$ \\
\hline & & c. $1294 C>T$ & p.(Met247Thr) & Yes & Not investigated & 82 & $0 / 0$ & $0 / 0$ & $0 / 0$ \\
\hline & & c. $1786 \mathrm{C}>\mathrm{T}$ & p.(Ala411Val) & No & Not investigated & 82 & $0 / 12$ & $0 / 10$ & $0 / 22$ \\
\hline \multirow[t]{4}{*}{ GATA6 } & $\begin{array}{l}\text { Transcription } \\
\text { factor }\end{array}$ & c. $617 \mathrm{~A}>\mathrm{C}$ & p.(GIn206Pro) & Yes & Not investigated & 86 & $0 / 0$ & $0 / 0$ & $0 / 0$ \\
\hline & & c. $704 \mathrm{~A}>\mathrm{C}$ & p.(Tyr235Ser) & Yes & Loss-of-function & 87 & $0 / 0$ & $0 / 0$ & $0 / 0$ \\
\hline & & c. $795 \mathrm{C}>\mathrm{G}$ & p.(Tyr265Ter) & Yes & Not investigated & 86 & $0 / 0$ & $0 / 0$ & $0 / 0$ \\
\hline & & c. $1406 \mathrm{G}>\mathrm{T}$ & p.(Gly469Val) & Yes & Loss-of-function & 88 & $0 / 0$ & $0 / 0$ & $0 / 0$ \\
\hline \multirow[t]{4}{*}{ LMNA } & Lamin A/C & $c .78 \mathrm{C}>\mathrm{T}$ & p.(Ile26lle) & $?$ & $?$ & 91 & $0 / 2$ & $0 / 0$ & $0 / 2$ \\
\hline & & c. $832 \mathrm{G}>\mathrm{A}$ & p.(Ala278Thr) & Yes & Not investigated & 90 & $0 / 0$ & $0 / 0$ & $0 / 0$ \\
\hline & & c. $1462 A>C$ & p.(Thr488Pro) & No & Not investigated & 128 & $0 / 0$ & $0 / 0$ & $0 / 0$ \\
\hline & & c. $1583 \mathrm{C}>\mathrm{T}$ & p.(Thr528Met) & Yes & Not investigated & 91 & $0 / 0$ & $0 / 0$ & $0 / 0$ \\
\hline NKX2-5 & $\begin{array}{l}\text { Transcription } \\
\text { factor }\end{array}$ & $c .434 \mathrm{~T}>\mathrm{C}$ & p.(Phe145Ser) & Yes & Not investigated & 117 & $0 / 0$ & $0 / 0$ & $0 / 0$ \\
\hline GREM2 & $\begin{array}{l}\text { BMP } \\
\text { antagonist }\end{array}$ & c. $226 \mathrm{C}>\mathrm{G}$ & p.(Gln76Glu) & No & $\begin{array}{l}\text { Increase in inhibi- } \\
\text { tory effect }\end{array}$ & 92 & $0 / 27$ & $0 / 4$ & $0 / 31$ \\
\hline
\end{tabular}

Abbreviations: AA, African American; EA, European American; ESP, NHLBI GO Exome Sequencing Project.

asomatic mutations.

(p.(Ala96Ser)), first detected by Gollob et a ${ }^{94}$. Yang et a ${ }^{96,97}$ and Sun et $a l^{98}$ have identified additional germline mutations in GJA5 (see Table 4).

\section{BIOINFORMATICS}

With the recently published exome data from the NHLBI GO ESP, knowledge regarding genetic variation in the general population has become available. ESP currently holds genetic information on approximately 6500 (2200 African Americans and 4300 European Americans) unrelated individuals obtained by next-generation sequencing (NGS) of DNA from individuals recruited from different population studies. ${ }^{99}$ No clinical data except from ethnicity were available in the ESP population, nor on request. Refsgaard et al $l^{100-103}$ have recently conducted a number of studies that indicate that the exome database is representative for genetic variation in healthy subjects. All rare variants so far associated with AF (see Tables 2-4) and hypothesized to be important susceptibility variants in AF were systematically searched for in the ESP population. As illustrated by the last three columns in Tables $2-4$, the vast majority of rare variants associated with AF were not present in the ESP population supporting that these variants are not random findings in original studies but indeed disease-causing or susceptibility mutations. If we make $a(n)$ (arbitrary) cutoff point regarding prevalence of the variants in ESP at $0.5 \%$ of the total alleles corresponding to $1 \%$ of individuals (wary set) only p.(Ser422Leu) (KCNJ8), p.(Ser216Leu), p.(Leu461Val), p.(Arg481Trp), p.(Ser524Tyr), p.(Ala572Val), p.(Leu618Phe), p.(Arg1193Gln) and p.(Phe2004Leu) (SCN5A), p.(Ser64Arg) (NPPA), p.(Ala411Val) (GATA4) and p.(Gln76Glu) (GREM2) must be regarded as rare genetic variants less likely to be the major/monogenic cause of the disease. This is in contrast to four recently published articles concerning the prevalence in ESP of previously described mutations in genes involved in pathogenesis 
of long QT syndrome (LQTS), sudden infant death syndrome (SIDS), cardiomyopathy and BrS. Here the investigators found a very high prevalence of previously described mutations in the ESP population. These findings question the disease-causing role of some of these variants in LQTS, SIDS, cardiomyopathy and BrS. ${ }^{100-103}$

\section{GENETIC OVERLAP WITH OTHER CARDIAC DISEASES}

There is a large overlap between different genes involved in arrhythmic diseases such as LQTS, BrS, short QT syndrome (SQTS), SIDS, cardiomyopathy and AF. The majority of genes associated with AF have been associated with other arrhythmic diseases. LQTS has been associated with mutations in KCNQ1, ${ }^{104} \mathrm{KCNE1-3,}{ }^{104,105}$ KCNH2, ${ }^{104} \mathrm{KCNJ} 2,{ }^{104}$ and SCN5A. ${ }^{104} \mathrm{BrS}$ has been associated with mutations in KCNE3, ${ }^{106} \mathrm{KCNE5},{ }^{107} \mathrm{KCND} 3,{ }^{108} \mathrm{KCNH} 2,{ }^{109}$ $S C N 5 A,{ }^{110} S C N 1 B b^{74}$ and $S C N 3 B .{ }^{111}$ Mutations in KCNQ1, KCNH2 and KCNJ2 have been associated with SQTS. ${ }^{104}$ SIDS has been associated with mutations in KCNQ1, KCNE1-2, KCNH2, KCNJ8, $S C N 5 A, S C N 1 B, S C N 3 B$ and GJA1. ${ }^{101}$ Mutations in ABCC9,112 $S C N 5 A,{ }^{68} N P P A^{113}$ and $L M N A^{102}$ have been associated with cardiomyopathy. Accordingly, nine genes associated with AF have not been associated with other arrhythmic diseases (KCNE4, KCNA5, SCN2B, NUP155, GJA5, GATA4, GATA6, NKX2-5 and GREM2). A conclusion could be that these genes are special for AF. Another explanation is simply that the genes have only been investigated in AF cohorts.

Patients with genetically proven SQTS or LQTS have a higher risk of early-onset AF than the general population. ${ }^{114,115}$ In a study by Johnson et al, ${ }^{114}$ early-onset AF was observed in almost $2 \%$ of patients with genetically proven LQTS compared with the background prevalence of $0.1 \%$. Interestingly, we recently found that both shortened and prolonged QTc interval durations are risk factors for incident $\mathrm{AF}$, and that the association was strongest with respect to lone AF. Thus, the QTc interval does not simply seem to be a marker of cardiac disease but instead seems to be an inherent characteristic of an individual's cardiac electrophysiology. Thereby, indicating a link between $\mathrm{AF}$ and patients with extremes of QTc interval. ${ }^{116}$

\section{EVIDENCE FOR INTERACTION BETWEEN COMMON AND RARE GENETIC VARIANTS}

Although traditional linkage analysis and candidate gene approaches have revealed numerous suspected disease-causing mutations in familial AF, penetrance in these families is highly variable. Moreover, the transmission mode of other forms of AF, although studies suggest a high degree of heritability, remains unclear. This indicates that $\mathrm{AF}$ inheritance is complex and in many cases non-Mendelian.

A recent study by Ritchie et al ${ }^{117}$ provide strong evidence that common genetic variants act as modifiers of rare genetic variants associated with familial AF. They studied whether the two previously reported common polymorphism in the chromosome $4 \mathrm{q} 25$ region ${ }^{15}$ contribute to the variable penetrance of familial AF. DNA sequence analysis was performed for KCNQ1, KCNA5, NKX2-5, SCN5A and NPPA. They identified 11 families in which AF was present in $\geq 2$ members and who also shared a mutation in one of the mentioned genes. Six families were found with rare variants in SCN5A, one with rare variants in NKX2.5, two with rare variants in NPPA, one with rare variants in KCNQ1 and one family with a rare variant in KCNA5. The penetrance of AF in probands carrying the putative mutation was low. However, the investigators found a significant interaction between common and rare genetic variants and onset of AF suggesting that addition of $4 \mathrm{q} 25$ genotypes helped predict, which carriers of the rare variants developed AF.
Another recent study by Mann et $a l^{57}$ showed epistatic effects of potassium channel variation on cardiac repolarization and AF risk. The major cardiac $\mathrm{K}^{+}$channels were sequenced and 19 nonsynonymous variants in 9 genes were found, 11 of them rare (6 of them novel). In all, 60 of the 80 AF probands had 2 or more variants. Individually, the variants had modest effect on potassium current but combinations of different variants showed both shortening end lengthening of APD suggesting a cumulative effect of ion channel variants both with regard to rare and common variants.

Olesen et $a l^{118}$ just recently added further evidence for an interaction between common and rare genetic variants. In a lone AF patient, a mutation in KCND3 was identified. Moreover, the patient was homozygous for the risk allele at both the ZFHX3 (rs2106261) and KCNN3 (rs13376333) loci, indicating that the patient was predisposed by common variants.

\section{GENETIC TESTING IN AF}

Ackerman et al ${ }^{119}$ stated the recommendations for genetic testing in channelopathies and cardiomyopathies in a Heart Rhythm Society/ European Heart Rhythm Society expert consensus document. Despite the high number of genes related to AF, the authors stated that genetic testing is not indicated for AF because none of the known diseaseassociated genes have been shown to account for $\geq 5 \%$ of the disease. Moreover, although several SNPs have been associated with AF, little information links these specific genetic variants to distinct clinical outcomes for AF. However, a newly published article by Everett et al ${ }^{120}$ added new knowledge regarding the link between SNPs and clinical outcome. The authors derived and validated a novel risk prediction model from 32 possible predictors in a cohort of 20822 women without cardiovascular disease at baseline. A genetic risk score was created, which comprised the nine loci discussed in the section 'The role of common genetic variants'. The addition of genetic score to the AF risk algorithm model improved the c-index. This suggests that common variants in future could be used for risk stratification. Furthermore, genetic testing in AF could be an opportunity in near future with the implementation of NGS where whole genomes can be sequenced in few days.

Specific variants detected in patients, could potentially predict whether or not the patient will have a beneficial response to a specific drug. Thereby, genetic information may be used in personalized medicine in the future.

\section{SUMMARY}

In recent years, the evidence concerning the genetic basis of AF has been rapidly increasing. Many monogenic mutations or rare variants have been revealed by candidate gene approaches. Although useful in understanding the pathophysiology of $\mathrm{AF}$, these mutations or rare variants are limited in explaining the heritability of AF because they only account for sporadic or familial cases of AF. GWAS are powerful in identifying new loci associated with an increased risk for development of AF. In the last 5 years, nine non-coding SNPs have been associated with increased risk of AF. These SNPs are believed to be signals for the causative genes. The genes in closest proximity to these SNPs have therefore been investigated and given new and valuable knowledge. However, the exact biological pathway between these non-coding SNPs and the emergence of AF still remains unsolved.

The new knowledge from the exome project and the implementation of NGS will hopefully make it possible to gain further insight to our understanding of AF. 


\section{CONFLICT OF INTEREST}

The authors declare no conflict of interest.

\section{ACKNOWLEDGEMENTS}

This study was funded by grants from the John and Birthe Meyer Foundation, the Arvid Nilsson Foundation, the Director Ib Henriksens Foundation, the Villadsen Family Foundation and the stock broker Henry Hansen and wife Karla Hansen, born Westergaard.

1 Go AS, Hylek EM, Phillips KA et al: Prevalence of diagnosed atrial fibrillation in adults: national implications for rhythm management and stroke prevention: the AnTicoagulation and Risk Factors in Atrial Fibrillation (ATRIA) Study. JAMA 2001; 285: 2370-2375.

2 Lloyd-Jones D, Adams RJ, Brown TM et al: Executive summary: heart disease and stroke statistics-2010 update: a report from the American Heart Association. Circulation 2010; 121: 948-954.

3 Benjamin EJ, Wolf PA, D'Agostino RB, Silbershatz H, Kannel WB, Levy D: Impact of atrial fibrillation on the risk of death: the Framingham Heart Study. Circulation 1998; 98: 946-952

4 Psaty BM, Manolio TA, Kuller LH et al: Incidence of and risk factors for atrial fibrillation in older adults. Circulation 1997; 96: 2455-2461.

5 Fuster V, Rydén LE, Cannom DS et al: ACCF/AHA/HRS focused updates incorporated into the ACC/AHA/ESC 2006 Guidelines for the management of patients with atrial fibrillation: a report of the American College of Cardiology Foundation/American Heart Association Task Force on Practice Guidelines developed in partnership with the European Society of Cardiology and in collaboration with the European Heart Rhythm Association and the Heart Rhythm Society. J Am Coll Cardiol 2011; 57: e101-e198.

6 Mahida S, Lubitz SA, Rienstra M, Milan DJ, Ellinor PT: Monogenic atrial fibrillation as pathophysiological paradigms. Cardiovasc Res 2011; 89: 692-700.

7 Arnar DO, Thorvaldsson S, Manolio TA et al: Familial aggregation of atrial fibrillation in Iceland. Eur Heart J 2006; 27: 708-712.

8 Christophersen IE, Ravn LS, Budtz-Joergensen E et al: Familial aggregation of atrial fibrillation: a study in Danish twins. Circ Arrhythm Electrophysiol 2009; 2: 378-383.

9 Darbar D, Herron KJ, Ballew JD et al: Familial atrial fibrillation is a genetically heterogeneous disorder. J Am Coll Cardiol 2003; 41: 2185-2192.

10 Ellinor PT, Yoerger DM, Ruskin JN, MacRae CA: Familial aggregation in lone atrial fibrillation. Hum Genet 2005; 118: 179-184.

11 Fox CS, Parise H, D'Agostino RB Sr et al: Parental atrial fibrillation as a risk factor for atrial fibrillation in offspring. JAMA 2004; 291: 2851-2855.

12 Lundby A, Ravn LS, Svendsen JH, Hauns S, Olesen S-P, Schmitt N: KCNE3 mutation V17M identified in a patient with lone atrial fibrillation. Cell Physiol Biochem 2008; 21: 47-54.

13 Ravn LS, Aizawa Y, Pollevick GD et al: Gain of function in IKs secondary to a mutation in KCNE5 associated with atrial fibrillation. Heart Rhythm 2008; 5: 427-435.

14 Oyen N, Ranthe MF, Carstensen L et al: Familial aggregation of lone atrial fibrillation in young persons. J Am Coll Cardiol 2012; 60: 917-921.

15 Gudbjartsson DF, Arnar DO, Helgadottir A et al: Variants conferring risk of atrial fibrillation on chromosome 4q25. Nature 2007; 448: 353-357.

16 Benjamin EJ, Rice KM, Arking DE et al: Variants in ZFHX3 are associated with atrial fibrillation in individuals of European ancestry. Nat Genet 2009; 41: 879-881.

17 Ellinor PT, Lunetta KL, Glazer NL et al: Common variants in KCNN3 are associated with lone atrial fibrillation. Nat Genet 2010; 42: 240-244.

18 Ellinor PT, Lunetta KL, Albert CM et al: Meta-analysis identifies six new susceptibility loci for atrial fibrillation. Nat Genet 2012; 44: 670-675.

19 Franco D, Chinchilla A, Aránega AE: Transgenic insights linking pitx2 and atrial arrhythmias. Front Physiol 2012; 3: 206.

20 Kato K, Oguri M, Hibino T et al: Genetic factors for lone atrial fibrillation. Int J Mol Med 2007; 19: 933-939.

21 Chung M, Van Wagoner D, Smith J et al: Significant single nucleotide polymorphism associated with atrial fibrillation located on chromosome 4q25 in a whole genome association study and association with left atrial gene expression. Circulation 2008 118: S882.

22 Gage PJ, Suh H, Camper SA: Dosage requirement of Pitx2 for development of multiple organs. Development 1999; 126: 4643-4651.

23 Mommersteeg MTM, Brown NA, Prall OWJ et al: Pitx2c and Nkx2-5 are required for the formation and identity of the pulmonary myocardium. Circ Res 2007; 101: 902-909

24 Mandapati R, Skanes A, Chen J, Berenfeld O, Jalife J: Stable microreentrant sources as a mechanism of atrial fibrillation in the isolated sheep heart. Circulation 2000; 101: 194-199.

25 Haïssaguerre M, Jaïs $\mathrm{P}$, Shah DC et al: Spontaneous initiation of atrial fibrillation by ectopic beats originating in the pulmonary veins. N Engl J Med 1998; 339: 659-666

26 Kirchhof P, Kahr PC, Kaese S et al: PITX2c is expressed in the adult left atrium, and reducing Pitx $2 \mathrm{c}$ expression promotes atrial fibrillation inducibility and complex changes in gene expression. Circ Cardiovasc Genet 2011; 4: 123-133.
27 Chinchilla A, Daimi H, Lozano-Velasco E et al: PITX2 insufficiency leads to atrial electrical and structural remodeling linked to arrhythmogenesis. Circ Cardiovasc Genet 2011; 4: 269-279.

28 Liu X, Wang F, Knight AC, Zhao J, Xiao J: Common variants for atrial fibrillation: results from genome-wide association studies. Hum Genet 2012; 131: 33-39.

29 Xiao J, Liang D, Chen Y-H: The genetics of atrial fibrillation: from the bench to the bedside. Annu Rev Genomics Hum Genet 2011; 12: 73-96.

30 Ido A, Miura Y, Watanabe $\mathrm{M}$ et al: Cloning of the cDNA encoding the mouse ATBF1 transcription factor. Gene 1996; 168: 227-231.

31 Ozgen N, Dun W, Sosunov EA et al: Early electrical remodeling in rabbit pulmonary vein results from trafficking of intracellular SK2 channels to membrane sites. Cardiovasc Res 2007; 75: 758-769.

32 Gratton J-P, Bernatchez P, Sessa WC: Caveolae and caveolins in the cardiovascular system. Circ Res 2004; 94: 1408-1417.

33 Zhao Y-Y, Liu Y, Stan R-V et al: Defects in caveolin-1 cause dilated cardiomyopathy and pulmonary hypertension in knockout mice. Proc Natl Acad Sci USA 2002; 99: $11375-11380$.

34 Pfeufer A, Van Noord C, Marciante KD et al: Genome-wide association study of PR interval. Nat Genet 2010; 42: 153-159.

35 Ihida-Stansbury K, McKean DM, Gebb SA et al: Paired-related homeobox gene Prx is required for pulmonary vascular development. Circ Res 2004; 94: 1507-1514.

36 Mellad JA, Warren DT, Shanahan CM: Nesprins LINC the nucleus and cytoskeleton. Curr Opin Cell Biol 2011; 23: 47-54.

37 Zhang Q, Bethmann C, Worth NF et al: Nesprin-1 and -2 are involved in the pathogenesis of Emery Dreifuss muscular dystrophy and are critical for nuclea envelope integrity. Hum Mol Genet 2007; 16: 2816-2833.

38 Herrmann S, Layh B, Ludwig A: Novel insights into the distribution of cardiac HCN channels: an expression study in the mouse heart. J Mol Cell Cardiol 2011; 51: 997-1006.

39 Schulze-Bahr E, Neu A, Friederich $\mathrm{P}$ et al: Pacemaker channel dysfunction in a patient with sinus node disease. J Clin Invest 2003; 111: 1537-1545.

40 Milanesi R, Baruscotti M, Gnecchi-Ruscone T, DiFrancesco D: Familial sinus bradycardia associated with a mutation in the cardiac pacemaker channel. $N$ Engl J Med 2006; 354: 151-157.

41 Beqqali A, Monshouwer-Kloots J, Monteiro R et al: CHAP is a newly identified Z-disc protein essential for heart and skeletal muscle function. J Cell Sci 2010; 123:Pt 7 1141-1150.

42 Brugada R, Tapscott T, Czernuszewicz GZ et al: Identification of a genetic locus for familial atrial fibrillation. N Engl J Med 1997; 336: 905-911.

43 Holm H, Gudbjartsson DF, Sulem P et al: A rare variant in MYH6 is associated with high risk of sick sinus syndrome. Nat Genet 2011; 43: 316-320.

44 Nattel S: New ideas about atrial fibrillation 50 years on. Nature 2002; 415 219-226.

45 Moe GK: Evidence for reentry as a mechanism of cardiac arrhythmias. Rev Physiol Biochem Pharmacol 1975; 72: 55-81.

46 Yang Y, Li J, Lin X et al: Novel KCNA5 loss-of-function mutations responsible for atrial fibrillation. J Hum Genet 2009; 54: 277-283.

47 Shiroshita-Takeshita A, Brundel BJJM, Nattel S: Atrial fibrillation: basic mechanisms, remodeling and triggers. J Interv Card Electrophysiol 2005; 13: 181-193.

48 Chen Y-H, Xu S-J, Bendahhou S et al: KCNQ1 gain-of-function mutation in familial atrial fibrillation. Science 2003; 299: 251-254.

49 Hong K, Piper DR, Diaz-Valdecantos A et al: De novo KCNQ1 mutation responsible for atrial fibrillation and short QT syndrome in utero. Cardiovasc Res 2005; 68 433-440.

50 Das S, Makino S, Melman YF et al: Mutation in the S3 segment of KCNQ1 results in familial lone atrial fibrillation. Heart Rhythm 2009; 6: 1146-1153.

51 Bartos DC, Duchatelet S, Burgess DE et al: R231C mutation in KCNQ1 causes long QT syndrome type 1 and familial atrial fibrillation. Heart Rhythm 2011; 8: 48-55.

52 Abraham RL, Yang T, Blair M, Roden DM, Darbar D: Augmented potassium current is a shared phenotype for two genetic defects associated with familial atrial fibrillation. J Mol Cell Cardiol 2010; 48: 181-190.

53 Otway R, Vandenberg JI, Guo G et al: Stretch-sensitive KCNQ1 mutation A link between genetic and environmental factors in the pathogenesis of atrial fibrillation? J Am Coll Cardiol 2007; 49: 578-586.

54 Bartos DC, Anderson JB, Bastiaenen R et al: A KCNQ1 mutation causes a high penetrance for familial atrial fibrillation. J Cardiovasc Electrophysiol 2012; 24: $562-569$

55 Olesen MS, Bentzen $\mathrm{BH}$, Nielsen JB et al: Mutations in the potassium channel subunit KCNE1 are associated with early-onset familial atrial fibrillation. BMC Med Genet 2012; 13: 24

56 Yang Y, Xia M, Jin $Q$ et al: Identification of a KCNE2 gain-of-function mutation in patients with familial atrial fibrillation. Am J Hum Genet 2004; 75: 899-905.

57 Mann SA, Otway R, Guo G et al: Epistatic effects of potassium channel variation on cardiac repolarization and atrial fibrillation risk. J Am Coll Cardiol 2012; 59: 1017-1025.

58 Hong K, Bjerregaard P, Gussak I, Brugada R, Short QT: syndrome and atrial fibrillation caused by mutation in KCNH2. J Cardiovasc Electrophysiol 2005; 16: 394-396.

59 Brugada R, Hong K, Dumaine R et al: Sudden death associated with short-QT syndrome linked to mutations in HERG. Circulation 2004; 109: 30-35.

60 Xia M, Jin Q, Bendahhou S et al: A Kir2.1 gain-of-function mutation underlies familial atrial fibrillation. Biochem Biophys Res Commun 2005; 332: 1012-1019.

61 Delaney JT, Muhammad R, Blair MA et al: A KCNJ8 mutation associated with early repolarization and atrial fibrillation. Europace 2012; 14: 1428-1432, European 
pacing, arrhythmias, and cardiac electrophysiology: journal of the working groups on cardiac pacing, arrhythmias, and cardiac cellular electrophysiology of the European Society of Cardiology.

62 Medeiros-Domingo A, Tan B-H, Crotti L et al: Gain-of-function mutation S422L in the KCNJ8-encoded cardiac K(ATP) channel Kir6.1 as a pathogenic substrate for J-wave syndromes. Heart Rhythm 2010; 7: 1466-1471.

63 Olson TM, Alekseev AE, Liu XK et al: Kv1.5 channelopathy due to KCNA5 loss-of-function mutation causes human atrial fibrillation. Hum Mol Genet 2006; 15: 2185-2191.

64 Yang Y, Lin X, Li J, Chen Y: [Identification and functional analysis of a KCNA5 mutation responsible for idiopathic atrial fibrillation]. Zhonghua Yi Xue Za Zhi 2010; 90: 1100-1104.

65 Yang T, Yang P, Roden DM, Darbar D: Novel KCNA5 mutation implicates tyrosine kinase signaling in human atrial fibrillation. Heart Rhythm 2010; 7: 1246-1252.

66 Christophersen IE, Olesen MS, Liang B et al: Genetic variation in KCNA5: impact on the atrial-specific potassium current IKur in patients with lone atrial fibrillation. Eur Heart J 2012; 34: 1517-1525.

67 Olson TM, Alekseev AE, Moreau C et al: KATP channel mutation confers risk for vein of Marshall adrenergic atrial fibrillation. Nat Clin Pract Cardiovasc Med 2007; 4 110-116.

68 Darbar D, Kannankeril PJ, Donahue BS et al: Cardiac sodium channel (SCN5A) variants associated with atrial fibrillation. Circulation 2008; 117: 1927-1935.

69 Olesen MS, Yuan L, Liang B et al: High prevalence of long QT syndrome associated SCN5A variants in patients with early-onset lone atrial fibrillation. Circ Cardiovasc Genet 2012: 5: 450-459.

70 Watanabe H, Darbar D, Kaiser DW et al: Mutations in sodium channel beta1- and beta2-subunits associated with atrial fibrillation. Circ Arrhythm Electrophysiol 2009; 2: 268-275

71 Wang $\mathrm{P}$, Yang $\mathrm{Q}, \mathrm{Wu} \mathrm{X}$ et al: Functional dominant-negative mutation of sodium channel subunit gene SCN3B associated with atrial fibrillation in a Chinese GeneID population. Biochem Biophys Res Commun 2010; 398: 98-104.

72 Olesen MS, Jespersen T, Nielsen JB et al: Mutations in sodium channel $\beta$-subunit SCN3B are associated with early-onset lone atrial fibrillation. Cardiovasc Res 2011; 89: 786-793.

$73 \mathrm{Hu}$ D, Barajas-Martinez H, Burashnikov E et al: A mutation in the beta 3 subunit of the cardiac sodium channel associated with Brugada ECG phenotype. Circ Cardiovasc Genet 2009; 2: 270-278.

74 Olesen MS, Holst AG, Svendsen JH, Hauns $\varnothing$ S, Tfelt-Hansen J: SCN1Bb R214Q found in 3 patients: 1 with Brugada syndrome and 2 with lone atrial fibrillation. Heart Rhythm 2012; 9: 770-773.

75 Hu D, Barajas-Martínez H, Medeiros-Domingo A et al: A novel rare variant in SCN1Bb linked to Brugada syndrome and SIDS by combined modulation of $\mathrm{Na}(\mathrm{v}) 1.5$ and K(v)4.3 channel currents. Heart Rhythm 2012; 9: 760-769.

76 Zhang $\mathrm{X}$, Yang $\mathrm{H}$, Corydon MJ et al: Localization of a human nucleoporin 155 gene (NUP155) to the 5 p13 region and cloning of its cDNA. Genomics 1999; 57 $144-151$.

77 Oberti C, Wang L, Li L et al: Genome-wide linkage scan identifies a novel genetic locus on chromosome $5 \mathrm{p} 13$ for neonatal atrial fibrillation associated with sudden death and variable cardiomyopathy. Circulation 2004; 110: 3753-3759.

78 Zhang X, Chen S, Yoo S et al: Mutation in nuclear pore component NUP155 leads to atrial fibrillation and early sudden cardiac death. Cell 2008; 135: 1017-1027.

79 Epstein FH, Levin ER, Gardner DG, Samson WK: Natriuretic peptides. N Eng/ J Med 1998; 339: 321-328

80 Hodgson-Zingman DM, Karst ML, Zingman LV et al: Atrial natriuretic peptide frameshift mutation in familial atrial fibrillation. N Engl J Med 2008; 359: 158-165.

81 Zhang Y, Rath N, Hannenhalli S et al: GATA and Nkx factors synergistically regulate tissue-specific gene expression and development in vivo. Development 2007; 134: 189-198.

82 Posch MG, Boldt L-H, Polotzki M et al: Mutations in the cardiac transcription factor GATA4 in patients with lone atrial fibrillation. Eur J Med Genet 2010; 53: 201-203.

83 Yang $Y$-Q, Wang M-Y, Zhang X-L et al: GATA4 loss-of-function mutations in familial atrial fibrillation. Clin Chim Acta 2011; 412: 1825-1830.

84 Jiang J-Q, Shen F-F, Fang W-Y, Liu X, Yang Y-Q: Novel GATA4 mutations in lone atrial fibrillation. Int J Mol Med 2011; 28: 1025-1032.

85 Wang J, Sun Y-M, Yang Y-Q: Mutation spectrum of the GATA4 gene in patients with idiopathic atrial fibrillation. Mol Biol Rep 2012; 39: 8127-8135.

86 Yang $Y-Q$, Wang $X-H$, Tan H-W, Jiang W-F, Fang W-Y, Liu X: Prevalence and spectrum of GATA6 mutations associated with familial atrial fibrillation. Int J Cardiol 2012; 155: 494-496.

87 Yang Y-Q, Li L, Wang J et al: GATA6 loss-of-function mutation in atrial fibrillation. Eur J Med Genet 2012; 55: 520-526.

88 Li J, Liu W-D, Yang Z-L, Yang Y-Q: Novel GATA6 loss-of-function mutation responsible for familial atrial fibrillation. Int J Mol Med 2012; 55: 520-526.

89 Holaska JM: Emerin and the nuclear lamina in muscle and cardiac disease. Circ Res 2008; 103: 16-23.

90 Beckmann BM, Holinski-Feder E, Walter MC et al: Laminopathy presenting as familial atrial fibrillation. Int J Cardiol 2010; 145: 394-396.

91 Saj M, Dabrowski R, Labib S et al: Variants of the lamin A/C (LMNA) gene in non-valvular atrial fibrillation patients: a possible pathogenic role of the Thr528Met mutation. Mol Diagn Ther 2012; 16: 99-107.

92 Müller II, Melville DB, Tanwar V et al: Functional modeling in zebrafish demonstrates that the atrial-fibrillation-associated gene GREM2 regulates cardiac laterality, cardiomyocyte differentiation and atrial rhythm. Dis Model Mech 2012; 6: 332-341.

93 Thibodeau IL, Xu J, Li Q et al: Paradigm of genetic mosaicism and lone atrial fibrillation: physiological characterization of a connexin 43-deletion mutant identified from atrial tissue. Circulation 2010; 122: 236-244.

94 Gollob MH, Jones DL, Krahn AD et al: Somatic mutations in the connexin 40 gene (GJA5) in atrial fibrillation. N Engl J Med 2006; 354: 2677-2688.

95 Christophersen IE, Holmegard HN, Jabbari J et al: Rare variants in GJA5 are associated with early-onset lone atrial fibrillation. Can J Cardiol 2012; 29: $111-116$.

96 Yang $Y-Q$, Liu X, Zhang X-L et al: Novel connexin40 missense mutations in patients with familial atrial fibrillation. Europace 2010; 12: 1421-1427.

97 Yang $\mathrm{Y}-\mathrm{Q}$, Zhang X-L, Wang X-H et al: Connexin40 nonsense mutation in familial atrial fibrillation. Int J Mol Med 2010; 26: 605-610.

98 Sun $Y$, Yang $Y-Q$, Gong X-Q et al: Novel germline GJA5/connexin40 mutations associated with lone atrial fibrillation impair gap junctional intercellular communication. Hum Mutat 2013; 34: 603-609.

99 Exome Variant Server, NHLBI GO Exome Sequencing Project (ESP), Seattle, WA, USA (URL. http://evs.gs.washington.edu/EVS/) Accessed 1 February 2013

100 Refsgaard L, Holst AG, Sadjadieh G, Hauns $\varnothing$ S, Nielsen JB, Olesen MS: High prevalence of genetic variants previously associated with LQT syndrome in new exome data. Eur J Hum Genet 2012; 20: 905-908.

101 Andreasen C, Refsgaard L, Nielsen BN et al: Mutations in genes encoding cardiac ion channels previously associated with sudden infant death syndrome (SIDS) are present with high frequency in new exome data. Can J Cardiol, S0828-282X: 01514-0.

102 Andreasen C, Nielsen JB, Refsgaard L et al: New population-based exome data are questioning the pathogenicity of previously cardiomyopathy-associated genetic variants. Eur J Hum Genet 2013; 21: 918-928.

103 Risgaard B, Jabbari R, Refsgaard L et al: High prevalence of genetic variants previously associated with Brugada syndrome in new exome data. Clin Genet 2013; doi: $10.1111 /$ cge.12126.

104 Hedley PL, Jørgensen P, Schlamowitz S et al: The genetic basis of long QT and short QT syndromes: a mutation update. Hum Mutat 2009; 30: 1486-1511.

105 Ohno S, Toyoda F, Zankov DP et al: Novel KCNE3 mutation reduces repolarizing potassium current and associated with long QT syndrome. Hum Mutat 2009; 30 : 557-563.

106 Delpón E, Cordeiro JM, Núñez L et al: Functional effects of KCNE3 mutation and its role in the development of Brugada syndrome. Circ Arrhythm Electrophysiol 2008; 1: 209-218.

107 Ohno S, Zankov DP, Ding W-G et al: KCNE5 (KCNE1L) variants are novel modulators of Brugada syndrome and idiopathic ventricular fibrillation. Circ Arrhythm Electrophysiol 2011; 4: 352-361.

108 Giudicessi JR, Ye D, Tester DJ et al: Transient outward current (I(to)) gain-of-function mutations in the KCND3-encoded Kv4.3 potassium channel and Brugada syndrome. Heart Rhythm 2011; 8: 1024-1032.

109 Wilders R, Verkerk AO: Role of the R1135H KCNH2 mutation in Brugada syndrome. Int J Cardiol 2010; 144: 149-151.

110 Hedley PL, Jørgensen P, Schlamowitz S et al: The genetic basis of Brugada syndrome: a mutation update. Hum Mutat 2009; 30: 1256-1266.

111 Ishikawa T, Takahashi N, Ohno S et al: Novel SCN3B mutation associated with Brugada syndrome affects intracellular trafficking and function of Nav1.5. Circ J 2012; 77: 959-967.

112 Bienengraeber M, Olson TM, Selivanov VA et al: ABCC9 mutations identified in human dilated cardiomyopathy disrupt catalytic KATP channel gating. Nat Genet 2004; 36: 382-387.

113 Disertori M, Quintarelli S, Grasso M et al: Autosomal recessive atrial dilated cardiomyopathy with standstill evolution associated with mutation of natriuretic peptide precursor A. Circ Cardiovasc Genet 2013; 6: 27-36.

114 Johnson JN, Tester DJ, Perry J, Salisbury BA, Reed CR, Ackerman MJ: Prevalence of early-onset atrial fibrillation in congenital long QT syndrome. Heart Rhythm 2008; 5: 704-709.

115 Giustetto C, Schimpf R, Mazzanti A et al: Long-term follow-up of patients with short QT syndrome. J Am Coll Cardiol 2011; 58: 587-595.

116 Nielsen JB, Graff C, Pietersen A et al: J-shaped association between QTc interval duration and the risk of atrial fibrillation: results from the Copenhagen ECG Study. J Am Coll Cardiol 2013; S0735-1097: 01412-01415.

117 Ritchie MD, Rowan S, Kucera G et al: Chromosome 4q25 variants are genetic modifiers of rare ion channel mutations associated with familial atrial fibrillation. J Am Coll Cardiol 2012; 60: 1173-1181.

118 Olesen MS, Refsgaard L, Holst AG et al: A novel KCND3 gain-of-function mutation associated with early-onset of persistent lone atrial fibrillation. Cardiovasc Res 2013; 98: 488-495.

119 Ackerman MJ, Priori SG, Willems S et al: HRS/EHRA expert consensus statement on the state of genetic testing for the channelopathies and cardiomyopathies this document was developed as a partnership between the Heart Rhythm Society (HRS) and the European Heart Rhythm Association (EHRA). Heart Rhythm 2011; 8: $1308-1339$.

120 Everett BM, Cook NR, Conen D, Chasman DI, Ridker PM, Albert CM: Novel genetic markers improve measures of atrial fibrillation risk prediction. Eur Heart J 2013. 
121 Fodstad H, Bendahhou S, Rougier J-S et al: Molecular characterization of two founder mutations causing long QT syndrome and identification of compound heterozygous patients. Ann Med 2006; 38: 294-304.

122 Arnestad M, Crotti L, Rognum TO et al: Prevalence of long-QT syndrome gene variants in sudden infant death syndrome. Circulation 2007; 115 361-367.

123 Ackerman MJ, Siu BL, Sturner WQ et al: Postmortem molecular analysis of SCN5A defects in sudden infant death syndrome. JAMA 2001; 286: 2264-2269.

124 Olson TM, Michels VV, Ballew JD et al: Sodium channel mutations and susceptibility to heart failure and atrial fibrillation. JAMA 2005; 293: 447-454.
125 Li Q, Huang H, Liu G et al: Gain-of-function mutation of Nav1.5 in atrial fibrillation enhances cellular excitability and lowers the threshold for action potential firing. Biochem Biophys Res Commun 2009; 380: 132-137.

126 Makiyama T, Akao M, Shizuta S et al: A novel SCN5A gain-of-function mutation M1875T associated with familial atrial fibrillation. J Am Coll Cardiol 2008; 52: 1326-1334.

127 Ellinor PT, Nam EG, Shea MA, Milan DJ, Ruskin JN, MacRae CA: Cardiac sodium channel mutation in atrial fibrillation. Heart Rhythm 2008; 5: 99-105.

128 Brauch KM, Chen LY, Olson TM: Comprehensive mutation scanning of LMNA in 268 patients with lone atrial fibrillation. Am J Cardiol 2009; 103 $1426-1428$. 